\title{
Capacitive behaviour in Super Junction Trench MOSFET devices
}

\author{
A. Villamor, I. Cortés, D. Flores \\ System Integration Department \\ IMB-CNM-CSIC \\ Campus UAB, 08193 Bellaterra, Barcelona, Spain \\ ana.villamor@imb-cnm.csic.es
}

\begin{abstract}
This paper exploits for the first time the capacitive behaviour of Super Junction (SJ) Trench Power MOSFETs as a characterization method to determine their Charge Balance (CB). Differently from blocking voltage methods, the capacitive method allows the CB extraction in $800 \mathrm{~V}$ SJ devices by using low voltage systems $(<30 \mathrm{~V})$ to extract the drain-source capacitance $\left(C_{d s}\right)$ in function of the drain-source voltage $\left(V_{d s}\right)$. Hence, the device-under-test is never stressed in avalanche, avoiding device degradation and/or destruction. The correlation between the minimum $\mathrm{C}_{\mathrm{ds}}$ value at $25 \mathrm{~V}$ and the optimum $\mathrm{CB}$ is demonstrated by TCAD simulations and measurements. As a result, the highest breakdown voltage $\left(\mathrm{V}_{\mathrm{bd}}\right)$, corresponding to the optimum $\mathrm{CB}$, is determined by measuring $\mathrm{C}_{\mathrm{ds}}$ at $25 \mathrm{~V}$. Moreover, the maximum $V_{d s}$ pinch voltage $\left(V_{\text {pinch }}\right)$ exhibits a maximum value when $\mathrm{C}_{\mathrm{ds}}$ at $25 \mathrm{~V}$ is minimum, thus also being an interesting parameter to monitor.
\end{abstract}

Keywords - Trench, Super-Junction, Charge Balance

\section{INTRODUCTION}

One of the key parameters in a conventional power MOSFET is the specific on resistance value $\left(\mathrm{R}_{\mathrm{DS}} \cdot \mathrm{A}\right)$, which has been improved with the Super Junction (SJ) concept. It consists of the substitution of the low doped $\mathrm{N}$ drift region by alternating thin columns of opposite doping type. The addition of the $\mathrm{P}$ column modifies the depletion process and the electric field distribution. The highest $\mathrm{V}_{\mathrm{bd}}$ is reached when a charge balance $(\mathrm{CB})$ of both $\mathrm{N}$ and $\mathrm{P}$ columns is set $[1,2,3]$.

In this work, a method to determine the real $\mathrm{CB}$ in a fabricated SJ structure is proposed, avoiding the possible destruction of the device by the conventional $\mathrm{V}_{\mathrm{bd}}$ measurement technique. The SJ trench MOSFET is briefly described and its depletion at low drain bias is analyzed. It is demonstrated by TCAD simulations and measurements that the $\mathrm{V}_{\mathrm{bd}}$ value can be estimated by measuring the drain-source capacitance $\left(\mathrm{C}_{\mathrm{ds}}\right)$ at $25 \mathrm{~V}$.

\section{DEVICE STRUCTURE AND MEASUREMENT SET-UP DESCRIPTION}

\section{A. Device structure}

A SJ trench MOSFET $[4,5]$ has been studied and fabricated, in contrast to using the multi-epitaxial/multi-implant process

\author{
J. Roig, F. Bogman, P. Vanmeerbeek, P. Moens \\ Power Technology Center - Corp. R\&D \\ ON Semiconductor \\ Westerring 15 B-9700 Oudenaarde, Belgium
}

(as the so-called CoolMOS [6]). The SJ trench structure, shown in Fig. 1, consists on vertical $\mathrm{N}$ and P-type layers selectively grown on the sidewalls of a deep trench, which is implemented in a lightly doped substrate $\left(\mathrm{N}^{-}\right.$epi $)$. The trench is sealed with oxide after the last epitaxial layer growth. The bottom of the $\mathrm{N}^{+}$pillar is connected to the high doped substrate $\mathrm{N}_{\text {sub }}^{+}$. The $\mathrm{P}_{\text {body }}$ diffusion is connected to the source electrode and implements the channel of the MOSFET. The top of the $\mathrm{P}$ pillar is connected to the $\mathrm{P}_{\text {body }}$ diffusion. The $\mathrm{N}_{\text {link }}$ diffusion allows the connection between the $\mathrm{N}$ pillar and the bottom of the gate trench. In the on-state the current will flow from the $\mathrm{N}_{\text {link }}$ and it will go into the $\mathrm{N}$ pillar. In the off-state the $\mathrm{N}_{\text {epi }}^{-}$layer handles the high drain voltage.

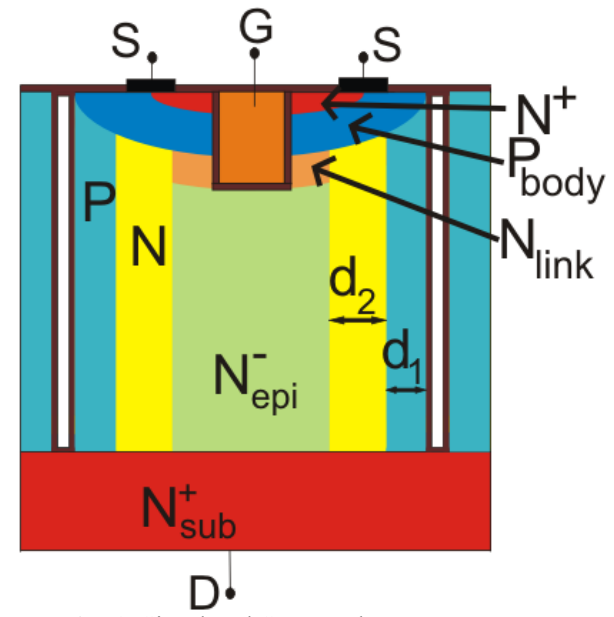

Fig. 1. Simulated SJ Trench structure

The device has different $\mathrm{N}$ and $\mathrm{P}$ regions, and the charge between all of them has to be balanced to obtain an equipotential lines distribution perfectly horizontal in the depleted region, at high drain applied bias. The result of this balance is a high $\mathrm{V}_{\mathrm{bd}}$ when the optimum $\mathrm{CB}$ is set, obtaining a lower $\mathrm{R}_{\mathrm{ON}}$ than a conventional VDMOS due to the high $\mathrm{N}$ pillar donor concentration. The $\mathrm{CB}$ is set according to Eq. 1 (normally expressed in \%). The concentration of the $\mathrm{N}$ pillar is defined as $\mathrm{N}_{\text {dose }}$ and the concentration of the $\mathrm{P}$ pillar as $\mathrm{P}_{\text {dose }}$.

$$
C B=\frac{\left(P_{\text {dose }} * d 1\right)-\left(N_{\text {dose }} * d 2\right)}{\left(N_{\text {dose }} * d 2\right)}
$$


TCAD simulations have been performed in the SJ Trench Power MOSFET structure. The DIOS platform [7] is used to simulate the technological process flow of the structure plotted in Fig.1, whereas the SDevice is used to electrically simulate the structure obtained from the DIOS simulation, extracting the $V_{b d}$ value and the $C_{d s}-V_{d s}$ curve. The reported simulations and measurements are obtained from a transistor structure, sweeping the drain with grounded source and floating gate. The voltage sweep applied to the device to extract the $C_{d s}-V_{d s}$ curve has been done from 0 to $25 \mathrm{~V}$ with $0.5 \mathrm{~V}$ steps. The applied AC signal has a level of $0.26 \mathrm{~V}$ with a $10 \mathrm{kHz}$ frequency.

The DIOS simulations were performed according to the splits on the pillar doping level of the processed wafers, and compared with the experimental electrical performance to ensure accurate simulation results. Fig. 2 shows a comparison between measured $\mathrm{C}_{\mathrm{ds}}-\mathrm{V}_{\mathrm{ds}}$ and two simulated curves for different $\mathrm{CB}$ conditions. Notice that the experimental curve shape is very well replicated by the simulated ones.

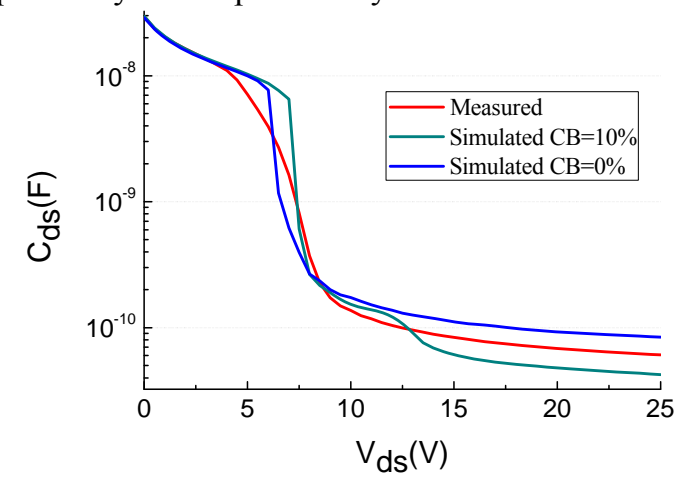

Fig. 2: Comparison between measured and simulated $C_{d s}-V_{d s}$ curves

The electrical parameters extracted from the $\mathrm{C}_{\mathrm{ds}}-\mathrm{V}_{\mathrm{ds}}$ curves are the capacitance at $0 \mathrm{~V}(\mathrm{C} @ 0 \mathrm{~V})$, the capacitance at $25 \mathrm{~V}$ $(\mathrm{C} @ 25 \mathrm{~V})$ and $\mathrm{V}_{\mathrm{ds}}$ pinch voltage $\left(\mathrm{V}_{\text {pinch }}\right)$, that is the voltage at which the capacitance has the maximum slope in the $\mathrm{C}_{\mathrm{ds}}-\mathrm{V}_{\mathrm{ds}}$ curve. $A \mathrm{dC}_{\mathrm{ds}} / \mathrm{C}_{\mathrm{ds}}$ curve used to determine the $\mathrm{V}_{\text {pinch }}$ value from the $\mathrm{C}_{\mathrm{ds}}-\mathrm{V}_{\mathrm{ds}}$ curve is calculated in one of the measured devices and shown in Fig. 3. The maximum $\mathrm{dC}_{\mathrm{ds}} / \mathrm{C}_{\mathrm{ds}}$ value is set as $\mathrm{V}_{\text {pinch }}$.

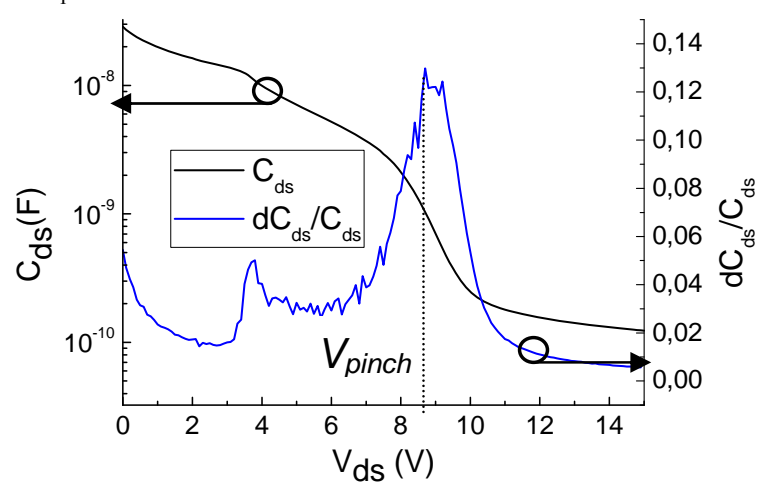

Fig. 3: Extraction of $\mathrm{V}_{\text {pinch }}$ from a $\mathrm{C}_{\mathrm{ds}}-\mathrm{V}_{\mathrm{ds}}$ measured curve. In this case $\mathrm{V}_{\text {pinch }}=8.8 \mathrm{~V}$.
The depletion behaviour of the SJ trench device has been analyzed from TCAD simulations in three different $\mathrm{CB}$ conditions: positive, negative and optimum. The $\mathrm{C}_{\mathrm{ds}}-\mathrm{V}_{\mathrm{ds}}$ curves for the three cases are shown in Fig. 4. All the curves exhibit an initial decrease of almost 2 decades at low drain applied bias (lower than 15V) because of the merging of the vertical and horizontal depletion regions. Nevertheless, the depletion expands into the $\mathrm{N}_{\text {epi }}^{-}$layer in a different way depending on the $\mathrm{CB}$ between the pillars, as reported in this section.

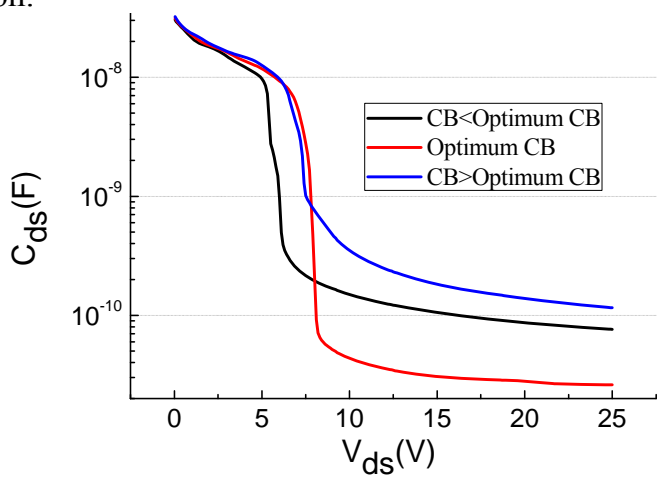

Fig. 4: Simulated $C_{d s}-V_{d s}$ curves for different $C B$ conditions. Notice that the minimal C@25V is reached when the CB is optimum.

The capacitance at high voltage $(100 \mathrm{~V})$ is the same for all cases since the capacitance can be deduced from Eq. 2 (being $d$ the depletion width and $l$ the extension of the depletion) [8].

$$
C_{d s}=\varepsilon_{s i} \frac{l}{d}
$$

The snapshots presented in Figs. 5-8 have been taken from the simulation of the $\mathrm{C}_{\mathrm{ds}}-\mathrm{V}_{\mathrm{ds}}$ curve at the region where $\mathrm{C}_{\mathrm{ds}}$ drops with $\mathrm{V}_{\mathrm{ds}}$. The white lines in the captured snapshots delimit the extension of the depletion region of the structure for an applied drain bias. It can be noticed that the separation between lines increases with the drain voltage, so $\mathrm{C}_{\mathrm{ds}}$ will be lower as a consequence of the increase of $d$. The capacitance value does not depend on $l$ since it is maximum from the very beginning. The $d$ value is maximal at $25 \mathrm{~V}$ when the $\mathrm{CB}$ is optimum, leading to the minimum $\mathrm{C}_{\mathrm{ds}}$ value.

\section{A. Optimum $C B(10 \%<C B<20 \%)$}

The expansion of the depletion process of both $\mathrm{P}$ and $\mathrm{N}$ pillars is completely symmetrical. The sharp drop of the $\mathrm{C}_{\mathrm{ds}}$ curve occurs at a drain bias between 7 and $8 \mathrm{~V}$, once the depletion region has reached the trench oxide in the right edge of the plotted structure. The $\mathrm{N}_{\text {epi }}^{-}$region is depleted due to the $\mathrm{P}$ pillar and the $\mathrm{P}_{\text {body }}$ donor compensation, after the top of the $\mathrm{N}$ pillar and the $\mathrm{N}_{\text {link }}$ are depleted. In Fig. 5 the fully depletion of the $\mathrm{N}$ pillar at the region close to the $\mathrm{N}_{\text {link }}$ can be observed, in which voltage the structure starts depleting vertically in the $\mathrm{N}_{\text {epi }}^{-}$layer. 

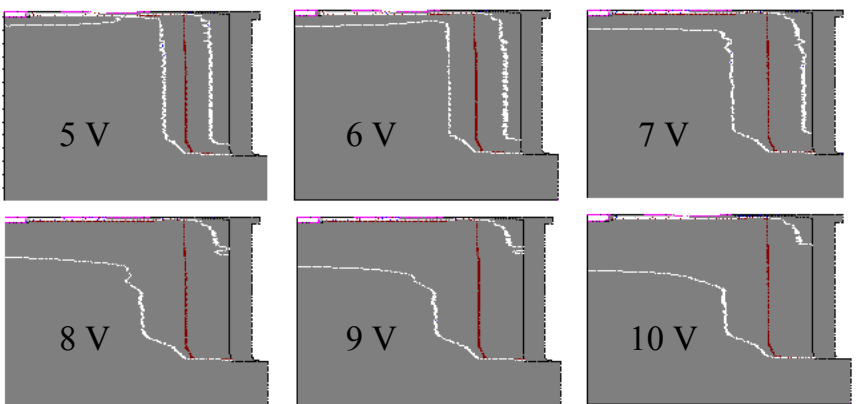

Fig. 5: Depletion in a SJ Trench structure at the Optimum CB case. X and $\mathrm{Y}$ are not drawn to scale.

\section{B. Higher $P_{\text {dose }}$ than $N_{\text {dose }}(C B>$ Optimum $C B)$}

With positive $\mathrm{CB}$, the depleted region does not reach the trench oxide until high drain voltage values are applied to the drain since more donors are needed to compensate the total charge of the $\mathrm{P}$ column. It can be envisaged from the snapshots of Fig. 6 that as the drain potential increases, the $\mathrm{N}_{\text {link }}$ diffusion and the $\mathrm{N}$ column are depleted and, before the extension of the depletion region reaches the trench oxide, the $\mathrm{N}_{\text {epi }}^{-}$is already depleted. As a consequence, the $\mathrm{C}_{\mathrm{ds}}$ drop is not so sharp since the lateral depletion through the $\mathrm{P}$ column is not completed, thus $d$ is not maximal.
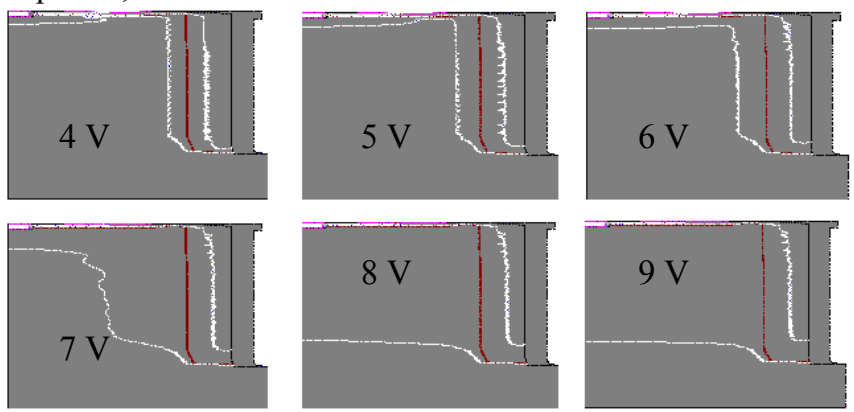

Fig. 6: Depletion in a SJ Trench structure at the Higher $P_{\text {dose }}$ than $N_{\text {dose }}$ case. $\mathrm{X}$ and $\mathrm{Y}$ are not drawn to scale.

\section{C. $\quad$ Higher $N_{\text {dose }}$ than $P_{\text {dose }}(C B<$ Optimum $C B)$}

As in the previous cases, the $\mathrm{P}_{\text {body }}$ region helps to deplete the $\mathrm{N}_{\text {link }}$ region. The $\mathrm{N}_{\text {link }}$ is fully depleted before the $\mathrm{N}$-column starts depleting, and that is when the vertical depletion between $\mathrm{P}_{\text {body }}$ and $\mathrm{N}_{\text {epi }}^{-}$also starts. The $\mathrm{C}_{\mathrm{ds}}$ drop happens when the vertical and lateral extension of the depletion region merge (between 5 and $6 \mathrm{~V}$, as shown in the zoom of Fig. 7), since the maximal $d$ can be taken into account in the top region of the $\mathrm{N}$ pillar. The snapshots of Fig. 8 clearly indicate that the $\mathrm{N}^{-}$epi region is not depleted at low drain bias.
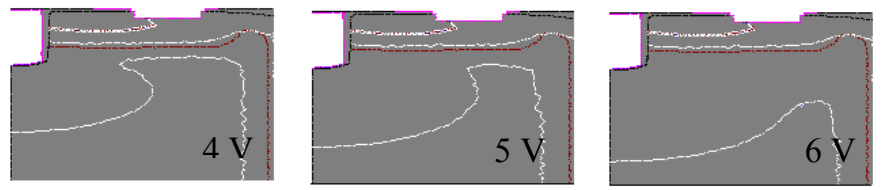

Fig. 7: Depletion zoom in a SJ Trench structure at the Higher $N_{\text {dose }}$ than $P_{\text {dose }}$ case. $\mathrm{X}$ and $\mathrm{Y}$ are not drawn to scale.
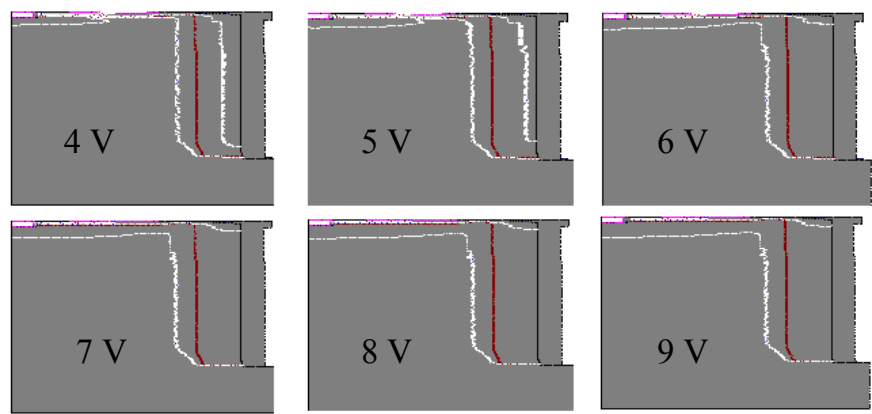

Fig. 8: Depletion in a SJ Trench structure at the Higher $N_{\text {dose }}$ than $P_{\text {dose }}$ case. $\mathrm{X}$ and $\mathrm{Y}$ are not drawn to scale.

It can be concluded that $\mathrm{V}_{\mathrm{bd}}$ is maximal when $\mathrm{C}_{\mathrm{ds}}$ is minimal due to the highest depletion of the lateral and vertical junctions. The sharp decrease observed in the $\mathrm{C}_{\mathrm{ds}}-\mathrm{V}_{\mathrm{ds}}$ curve is due to the merge of the lateral and vertical depletion regions. Moreover, the depletion of the $\mathrm{N}_{\text {link }}$ is faster with $\mathrm{CB}<$ Optimum $\mathrm{CB}$ than with $\mathrm{CB} \geq$ Optimum $\mathrm{CB}$ since more potential is needed to deplete the $\mathrm{N}$ pillar. It leads to a faster merging of the vertical and the lateral junctions; hence the $C_{\mathrm{ds}}$ $\mathrm{V}_{\mathrm{ds}}$ curve drops at lower drain voltage values. Finally, in the negative $\mathrm{CB}$ case the depletion of the $\mathrm{P}$ pillar is almost complete at low drain bias, and it contributes increasing the $d$ parameter, thus decreasing the $\mathrm{C}_{\mathrm{ds}}$ value.

\section{IV. $\quad \mathrm{C}_{\mathrm{DS}}-\mathrm{V}_{\mathrm{DS}}$ AND TECHNOLOGICAL PARAMETERS}

The $\mathrm{C}_{\mathrm{ds}}-\mathrm{V}_{\mathrm{ds}}$ simulated curves for different $\mathrm{N}_{\text {dose }}$ and $\mathrm{CB}=10 \%$ are plotted in Fig. 9. The capacitance curve shifts to the right when increasing the $\mathrm{N}_{\text {dose }}$, since more potential is needed to deplete the same area as with lower $\mathrm{N}_{\text {dose }}$. The shape of all curves is the same since the $\mathrm{P}_{\text {dose }}$ is also proportionally increased (same $\mathrm{CB}$ for all of them). The $\mathrm{V}_{\text {pinch }}$ values as a function of the $\mathrm{N}_{\text {dose }}$ from simulations and measurements are also plotted in Fig. 9. The small difference in the $V_{\text {pinch }}$ values between simulations and measurements, depending on the $\mathrm{N}_{\text {dose }}$, is due to the fact that in the fabricated transistors the $\mathrm{N}_{\text {dose }}$ is a little bit lower than expected. In both cases, the $\mathrm{V}_{\text {pinch }}$ value increases with the $\mathrm{N}_{\text {dose }}$ and, since $\mathrm{V}_{\text {bd }}$ increases when decreasing the $\mathrm{N}_{\text {dose }}$ as shown in Fig. 10, a trade-off between $\mathrm{N}_{\text {dose }}$ and $\mathrm{V}_{\text {bd }}$ has to be set, taking into account that a low $\mathrm{N}_{\text {dose }}$ leads to a high $\mathrm{R}_{\text {on }}$. The CB is set to the $10 \%$, since not just the pillars but the $\mathrm{N}^{-}$epi region have to be also depleted, thus more $\mathrm{P}$ is needed.

The relation between $\mathrm{V}_{\text {pinch }}$ and $\mathrm{V}_{\mathrm{bd}}$ is shown in Fig. 11, where the results of the measurements on devices implemented on wafers with different $\mathrm{N}_{\text {dose }}$ and different $\mathrm{CB}$ are plotted. From this graph it can be concluded that the lower $\mathrm{V}_{\text {pinch }}$ leads to a high $\mathrm{V}_{\mathrm{bd}}$. It makes sense since a low $\mathrm{V}_{\text {pinch }}$ means a low $\mathrm{N}_{\text {dose, }}$, thus for the non-optimal $\mathrm{CB}$, the $\mathrm{V}_{\mathrm{bd}}$ is higher (see Fig.10).

The evolution of $\mathrm{C}_{\mathrm{ds}} @ 25 \mathrm{~V}, \mathrm{~V}_{\text {pinch }}$ and $\mathrm{V}_{\mathrm{bd}}$ (scaled as $\mathrm{V}_{\mathrm{bd}} / 50$ ) over a whole row in a wafer of SJ Trench transistors is plotted in Fig. 12. The wafer was processed to do not have a 
uniform CB over the whole wafer, corroborating that $\mathrm{C}_{\mathrm{ds}} @ 25$ $\mathrm{V}$ is minimal when $\mathrm{V}_{\mathrm{bd}}$ is maximal. It can also be inferred that as expected, $V_{\text {pinch }}$ is following the $\mathrm{C}_{\mathrm{ds}}$ curve since the minimal $\mathrm{V}_{\text {pinch }}$ corresponds to the maximal $\mathrm{V}_{\text {bd }}$.

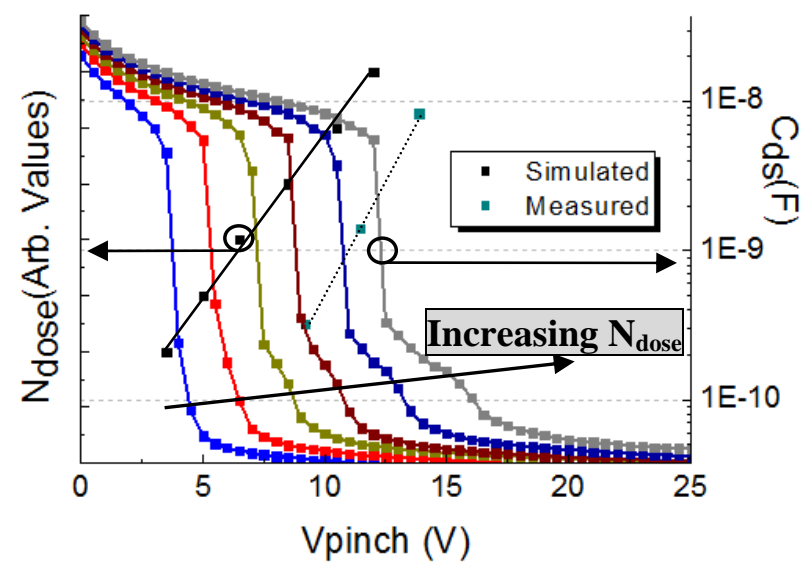

Fig. 9: Simulated $C_{d s}-V_{d s}$ curves for different $N_{\text {dose }}$ (being $N_{d o s e} 1$ the lower level and $\mathrm{N}_{\text {dose }} 6$ the higher). The squares correspond to $\mathrm{V}_{\text {pinch }}$ simulated and measured values for different $\mathrm{N}_{\text {dose }}$ level (left axis). Note that the tendency is the same for measurements and simulations.

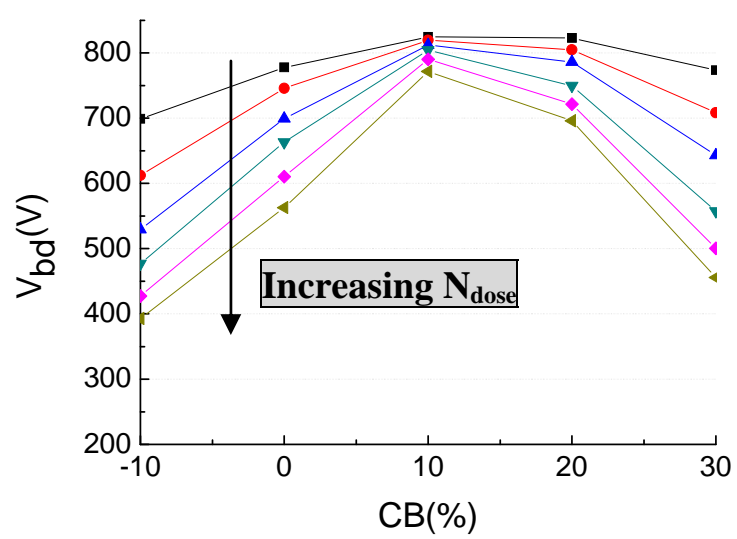

Fig. 10: Simulated $C B-V_{b d}$ trade-off for different $N_{\text {dose }}$ level. The maximum $\mathrm{V}_{\text {bd }}$ value is reached when the optimum $C B$ is set.

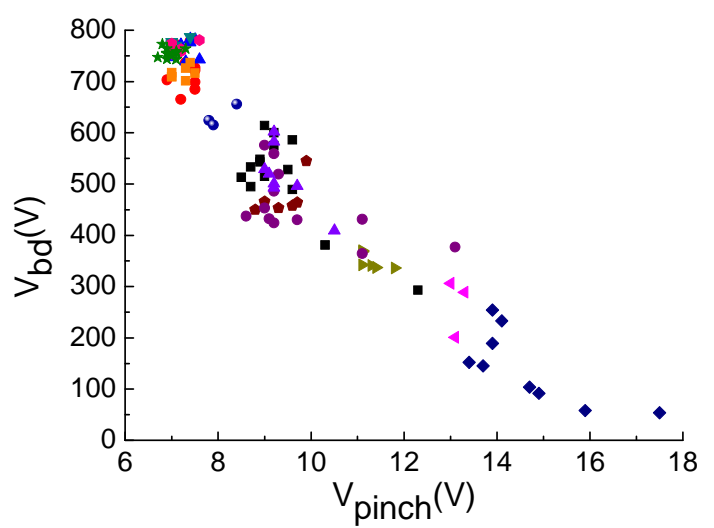

Fig. 11: $V_{b d}-V_{\text {pinch }}$ relation for measured $S J$ Trench transistors in the central row of processed wafers with different $\mathrm{N}_{\text {dose }}$

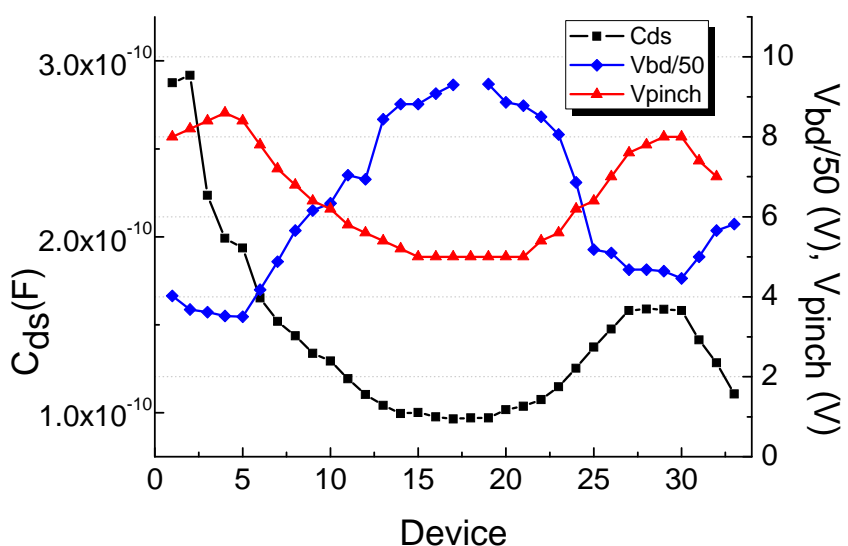

Fig. 12: $\mathrm{V}_{\mathrm{bd}} / 50, \mathrm{~V}_{\text {pinch }}$ and $\mathrm{C}_{\mathrm{ds}} @ 25 \mathrm{~V}$ for SJ Trench transistors in the central row of a wafer

\section{CONCLUSION}

The capacitive behaviour in Super Junction power MOSFETs has been studied to extract the charge balance and to predict the voltage capability of fabricated transistors without degrading the device. A relation between $\mathrm{C}_{\mathrm{ds}}-\mathrm{V}_{\mathrm{ds}}$ curves, $\mathrm{V}_{\text {pinch }}$ and $\mathrm{V}_{\mathrm{bd}}$ has been demonstrated with simulations and measurements on fabricated SJ trench power MOSFET devices. The capacitive behaviour has been described by the evolution of the depletion region when low drain voltage is applied. A good correlation between TCAD simulations and measurements has been obtained.

\section{REFERENCES}

[1] T. Fujihira, "Theory of semiconductor superjunction devices", Jpn.J.Appl.Phys., Vol. 36, pp.6254-6262, (1997)

[2] P.M. Shenoy, A. Bhalla, G. Dolny, "Analysis of the effect of charge imbalance on the static and dynamic characteristics of the super junction MOSFET", Proc. ISPSD 99, pp. 99-102, (1999)

[3] M. Bobde, L. Guan, A. Bhalla, F. Wang, M. Ho, "Analyzing SuperJunction C-V to estimate Charge Imbalance" Proc. ISPSD 10, pp. 321-324, (2010)

[4] M. Rüb, D. Ahlers, J. Baumgarlt, G. Deboy, W. Friza, O. Häberlen and I. Steinigke, "A novel trench concept for the fabrication of compensation devices", pp. 683-685, Proc. IEDM (1998)

[5] P.Moens et al., "Ultimos: A local Charge-Balanced Trench based $600 \mathrm{~V}$ Super-Junction device", ISPSD 2011: Accepted as oral presentation

[6] G. Deboy, M. Marz, J-P. Stengl. H. Sack, J. Tihanyi and H. Weber, "A new generation of high voltage MOSFETs breaks the limit line of silicon", pp. 683-685, Proc. IEDM (1998)

[7] Synopsys Manuals: Dios, Sentaurus Structure Editor, Sentaurus Device

[8] S. Srikanth and S. Karmalkar, "On the Charge Sheet Superjunction (CSSJ) MOSFET", IEEE Trans. Electron Devices, Vol. 55 N ${ }^{\circ} .12$ (2008) 